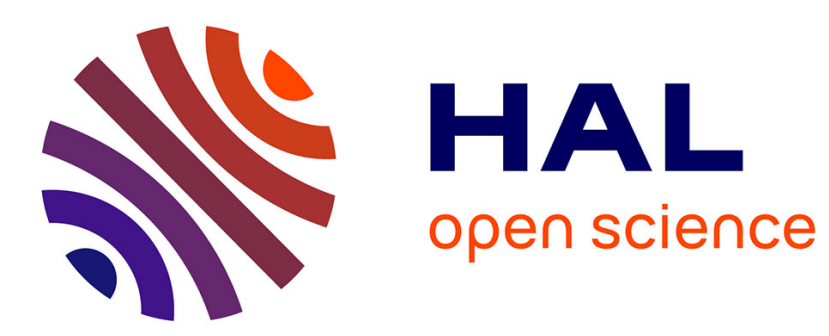

\title{
Is firm-sponsored training a palliative? A common agency approach
}

H. Lasram, Didier G. Laussel

\section{To cite this version:}

H. Lasram, Didier G. Laussel. Is firm-sponsored training a palliative? A common agency approach. Applied Economics, 2016, 48 (57), pp.5581-5592. 10.1080/00036846.2016.1181830 . hal-01448234

\section{HAL Id: hal-01448234 \\ https://hal-amu.archives-ouvertes.fr/hal-01448234}

Submitted on 7 Feb 2022

HAL is a multi-disciplinary open access archive for the deposit and dissemination of scientific research documents, whether they are published or not. The documents may come from teaching and research institutions in France or abroad, or from public or private research centers.
L'archive ouverte pluridisciplinaire HAL, est destinée au dépôt et à la diffusion de documents scientifiques de niveau recherche, publiés ou non, émanant des établissements d'enseignement et de recherche français ou étrangers, des laboratoires publics ou privés. 


\title{
Is firm-sponsored training a palliative? A common agency approach
}

\author{
H. Lasram (10 ${ }^{\mathrm{a}, \mathrm{b}}$ and Didier G. Laussel ${ }^{\mathrm{b}}$ \\ aHEC and Unité MASE-ESSAI, Université de Carthage, Tunis, Tunisia; ${ }^{b}$ Aix-Marseille University (Aix-Marseille School of Economics), CNRS \& \\ EHESS, Aix en Provence, France
}

\begin{abstract}
We analyse the issue of firm-sponsored training under product market imperfections. In this setting, qualification becomes a public good for firms when their profits are increasing in the stock of skilled workers but remains a private good to students/workers. Students have to pay a tuition fee but at the same time firms sponsor education: universities sell training to both. We prove that the proportion of skilled workers is larger in more competitive economies/industries while the share of firms in the financing of training is a monotonically decreasing function of the degree of competition. An increase of the latter indeed increases the equilibrium skilled wage while reducing its sensitivity to an increase of the supply of skilled workers. The firms' aggregate expenditures on training per worker are nevertheless a nonmonotonic function of the competitiveness of the economy.
\end{abstract}

KEYWORDS Firm-sponsored training; education; product market imperfections; labour market

JEL CLASSIFICATION D43; I22; J4; L13

\section{Introduction}

Using rough 2008 data from OECD, ${ }^{1}$ the share of 'private entities other than households' ${ }^{2}$ in total 'tertiary education' ${ }^{3}$ expenditures is generally significant, while ranging from rather low levels in Ireland $(2.3 \%)$ or Belgium and Spain $(4.1 \%)$ to much higher ones in Portugal (9.2\%) or in Slovakia (13.8\%)(see Figure A1 in the Appendix). Interestingly enough, there also seems, over eight European countries for which both data are available, to be an inverse relationship between the relative contribution of 'private entities other than households' and the proportion of skilled workers $^{4}$ (i.e. by 'skilled workers' we mean here workers who received a tertiary education) in the working population, what could suggest that firmsponsored training could be a palliative to the financing of higher education by the other agents (households, governments). The present article provides a theoretical underpinning for such a negative association.
We consider more specifically the case where a University is sponsored by private companies for training students, rather than the one where companies sponsor students. Put otherwise, we deal in the main text with the case where the supply of training is sponsored rather than the demand for training. ${ }^{5}$

There are numerous examples of partnerships between universities and firms in order to train more skilled employees. Three Canadian cases are, for instance: first, the partnership between the University of Ontario's Institute of Technology and Ontario Power Generation which is intended to 'produce more employees for the Canadian nuclear industry'; second the partnership between Western University and a law firm, Cassels, Brock and Blackwell, to create a programme forming lawyers skilled in mining law and third the partnership between University of Toronto/ Pierre Lassonde and Goldcop Inc., which aims to 'accommodate a greater number of students and scholars' ${ }^{6}$ Sponsored degree programmes are offered in the UK by a growing number of prestigious firms: Airbus, Barclays Bank, Capgemini, Ernst and Young,

CONTACT H. Lasram hejer.lasram@gmail.com

${ }^{1}$ Data extracted from OECD.stat, Dataset: Expenditure by funding source and transaction type.

${ }^{2}$ That is, firms and nonprofit organizations.

${ }^{3}$ Total tertiary education includes types $\mathrm{A}$ and $\mathrm{B}$.

${ }^{4}$ The proportion of skilled workers is computed as the difference between skilled active population and skilled unemployment divided by total employment; data are extracted from ILO.stat (Source: Labor force survey).

${ }^{5}$ There is no contract between workers/students and sponsors-partners.

${ }^{6}$ Open For Business' (2013). 
Experian, KPMG, Morrisons, Nestle, PWC and UPS. ${ }^{7}$ On the other hand, more and more companies are offering scholarships to students training at universities, among which are Ernst \& Young, Google and Lloyds.

In our model training, besides being a public good from the firms' point of view, is a private good for students/workers, and is provided by specialized firms, say universities. We indeed consider that workers/students decide whether or not to train, given that they have to pay tuition fees if they choose to train. Training may be part-time, in-service, including internship periods, but is not training by firms alone. In a first stage, the firms propose to the University to sponsor workers' training. In the second one, the University accepts or rejects the proposals and sets the tuition fee and students decide whether or not to train. In the third stage, given the stock of workers already trained, the firms compete in wages to attract skilled workers. In the last stage, the firms buy other inputs and sell their output in the product market(s), resulting in profits which depend on the allocation of skilled labour. Following Bernheim and Whinston (1986), the first and the second stages of the game are modelled in a general way as the equilibrium of a common agency game of private production of a public good. ${ }^{8}$ Explicit solutions are obtained in the linear-quadratic example.

\section{Results}

A remarkable prediction of our model is a negative association at equilibrium between the proportion of skilled workers in the working population and the share of firms in aggregate training expenditures. They turn out to be linked through the 'degree of competitiveness' of the economy (or the industry): indeed, greater competitiveness, which makes training more valuable for students/workers, makes it less profitable for firms.

On the one hand, for any given proportion of skilled workers, an increase in the number of firms reduces the employment of skilled workers at each firm, raising the equilibrium wage and hence the workers' demand for training.

On the other hand, the share of firms ${ }^{9}$ in the financing of training is shown to be a monotonically decreasing function of the degree of competition. This is basically because firms' incentive to invest in training is greater the more this investment may reduce equilibrium skilled wage, i.e. the steeper is the inverse demand function for skilled labour, accordingly the less competitive the economy or industry.

To sum up, an increase in the degree of competition both increases the equilibrium skilled wage for any proportion of skilled workers, inducing more workers to train, and reduces the slope of the demand for skilled labour, leading firms to invest less in training. ${ }^{10}$

At the same time, the equilibrium tuition fee appears to be the larger, the more competitive is the economy.

\section{Related literature}

Earlier literature on this question has explained the interest of firms in the training of workers by labour market imperfections. Becker (1962, 1964) proved that when the labour market is perfectly competitive, firms are not interested in financing general training, insofar as under perfect competition the firm pays a wage which equals workers' productivity, so there is no benefit for the firms to invest in general training. This result was confirmed by Acemoglu and Pischke (1999a, 1999b). They pursued the analysis considering labour market imperfections due, for example, to search frictions (Acemoglu 1997) or due to asymmetric information between the employer, workers and competitors (Katz and Ziderman 1990; Chang and Wang 1995, 1996; Acemoglu and Pischke 1998). The authors showed that when labour market frictions reduce the wage of skilled workers below their marginal productivity level, yielding rents for employers, firms have an incentive to pay for general training. In that case, training raises workers' productivity more than wages so that employers' rents increase.

More recently, Gersbach and Shmutzler (2012) have explained firms' investment in training by a quite different argument. Firms would pay for workers' training in order to 'avoid having to pay too high wages for trained workers' (475). The focus is

\footnotetext{
${ }^{7}$ See http://thescholarshiphub.org.uk/blog/sponsored-degrees-uk.

${ }^{8}$ There have been numerous applications of the common agency model in different settings, notably to analyse lobbying issues (see Grossman and Helpman, 1994, regarding trade policy).

${ }^{9}$ Notice that the firms' aggregate expenditures on training per worker are a nonmonotonic function of the competitiveness of the economy.

${ }^{10}$ The inverse demand function shifts downward and its absolute slope decreases, for any number of skilled workers, when the degree of competition increases.
} 
no more on the incentive for a firm to finance the training of a particular worker but rather on the training of firms contributing 'to the reduction of wages that is responsible for training incentives' (488). The basic setting is an imperfectly competitive industry' with skills specific to that industry ${ }^{11}$. From the study of several examples of imperfectly competitive industries, the authors conclude that training may occur in equilibrium if 'competition is soft'. The intuition is that training also benefits to the competitors and that this all the more detrimental to the training firm the more severe is the competition with its rivals. Gersbach and Schmutzler therefore conclude that product market imperfections, besides labour market ones, may explain firms' expenditures on training. In our terminology, they showed that training is a public good from the firms' point of view when competition is soft.

Our article differs from Gersbach and Shmutzler's in several important respects. They explicitly consider training by firms alone whereas we analyse the case where training requires the participation of training institutions (universities), and where firms pay the universities to have them train more students. A first consequence is that while we can measure the impact of firms' financing on the number of skilled workers, it is impossible to identify workers who would be trained directly by the firms. A second one is that we are able to show that firms' and households' investments in training are substitutes: in more competitive settings, firms invest less while students/workers invest more in education. Our model may deal with the case where skills are partly useful across industries and within countries and not only across firms within a specific industry. ${ }^{12}$

Generally, the empirical evidence on the effect of product competition on firms' investment in training is still controversial. Autor (2001) and Bassanini and Brunello (2010), analysing firms' financing training, concluded that an increase in product competition affects positively firms' training investment. Others (Grlitz and Stiebale 2008; Picchio and Van Ours 2010) argued on the contrary that there is no competition effect on training.
These studies are trying to find evidence for the relationship between product competition and workplace training whereas our model points towards a relationship between competitiveness and the share of firms in training expenditures. Moreover, our article exhibits a nonmonotonic relationship between firms' expenditures on training per head and an indicator of the degree of product competition, firms' expenditures being small both in very competitive and in very noncompetitive circumstances. This may lead to conclusions which are only locally true. When one observes the level of firms' training expenditures corresponding to the degrees of competition in industries which are rather noncompetitive though at different degrees, one would conclude to a positive association between firms' expenditures and the degree of competition. The reverse conclusion would obtain from observing rather competitive industries. Thus, our model points out that empirical research should rather try to test the relationship between the share of firms in training expenditures and competitiveness.

The remainder of the article is organized as follows. Section II introduces the model. In Section III, we solve the third period competition in wages. In Section IV, we solve the common agency game. Section V analyses a linear-quadratic example. We conclude in Section VI. All proofs are given in the Appendix.

\section{The model}

We consider a model where $n$ identical ${ }^{13}$ firms compete in wage on the skilled labour market. The skills are not firm-specific. They may be industry-specific like in Gersbach and Schmutzler (2012) but not necessarily so. There are in a given economy several different markets for different types of skilled labour which are useful in possibly different industries. We analyse here one of these markets. Qualification is provided by a private University, and in order to become skilled, students/workers have to pay to the University a tuition fee and bear an individual training cost. Here, the supply of training is sponsored rather than the demand for training. Note that the

\footnotetext{
${ }^{11}$ In their conclusion, the authors acknowledge that the assumption of industry-specific training, useless outside the industry, 'is not decisive for the existence of a training equilibrium'. The same type of skilled may be indeed useful in several different industries.

${ }^{12}$ Gersbach and Schmutzler, while insisting on industry-specific skills, also allow for this possibility in the conclusion of their paper.

${ }^{13}$ Generalizing to account for different firms while not very difficult would complicate the analysis for few additional insights.
} 
qualitative results obtained can be extended to the case where the demand for training is sponsored. ${ }^{14}$

\section{Firms}

Each Firm $i$ employs a number $L_{i}$ of skilled workers and its gross profit function is simply $\Pi\left(L_{i}\right)$, which is increasing at a decreasing rate in the number of skilled workers employed, ${ }^{15}$ i.e. $\Pi^{\prime}\left(L_{i}\right)>0$ and $\Pi^{\prime \prime}\left(L_{i}\right)<0$. Assume that $\Pi(0) \geq 0$. The assumption $\Pi^{\prime \prime}\left(L_{i}\right)<0$ will prove to be the key assumption in this model. It corresponds to the assumption DRAW (Decreasing Returns to Attracting Workers) in Gersbach and Schmutzler (2012).

Firm $i$ fixes the wage $W_{i}$ to be paid to its employees and commits to hire all skilled workers who will be willing to work at this wage. Profits net of wages are then $V_{i}\left(L_{i}\right)=\Pi\left(L_{i}\right)-W_{i} L_{i}$. Firms are assumed to differ from the workers' point of view only by the wages they offer.

\section{The University}

It transforms an unskilled agent into a skilled one at a unit cost $c$. In order to become skilled, a student has to pay a tuition fee $t$, the level of which is fixed by the University. Skilled workers are assumed to be identical, i.e. perfect substitutes, from the firms' point of view. The University is assumed to maximize its profit.

\section{Students/workers}

A type $u$-student has a cost $u$ for training where $u$ is distributed on some interval according to a continuous distribution function $F$. When she chooses not to train, she expects to obtain some exogenous reservation utility, which, for the sake of simplicity, is normalized to 0 . When she chooses to train, she expects to obtain a net utility $W-t-u$, where $W$ is the wage she expects to earn when becoming skilled and $t$ the tuition fee paid to the University. It follows that the demand for training or, equivalently, the supply of skilled labour is simply

$$
L=L^{s}(W-t)=\bar{L} F(W-t)
$$

where $\bar{L}$ is the total working population. Of course, $L$ is strictly increasing in $W-t$. Given that any skilled worker has first to be trained, the supply of skilled labour is also the demand for training. For convenience, we shall use the inverse demand function for training, ${ }^{16}$

$$
W-t=F^{-1}\left(\frac{L}{\bar{L}}\right):=\omega\left(\frac{L}{\bar{L}}\right)
$$

Notice that $\omega\left(\frac{L}{L}\right)$ denotes the wage net of the tuition fee.

The timing of the game is as follows:

(1) Each firm proposes to the University to sponsor it, by an amount $T_{i}(L)$, which depends on the number $L$ of students trained at the University; we shall restrict our attention to the case where the firms use truthful strategies such as defined by Bernheim and Whinston (1986) or Laussel and Le Breton (2001) (Definition 2.1., 98). ${ }^{17}$

(2) The University chooses to accept all contract offers or only a subset of them or to reject all. Then it selects the number of students $L$ to be trained and the tuition fee $t$ under constraint (1) or, equivalently, (2). We assume that, doing so, it holds rational expectations about the third period average wage.

(3) The $L$ workers who have been trained at the second stage search for a skilled job under the only constraint to obtain a wage net of the tuition fee $\omega$ not lower than their (zero) reservation utility. The $n$ firms compete in wages to attract skilled workers.

\section{Third-period competition in wages}

In the last period, whatever the number of firms sponsoring the University, all the firms compete in wages to attract skilled workers $(L)$, under the only constraint to offer positive wages. We suppose that the firms which offer the highest wage share equally the supply of skilled workers between themselves

\footnotetext{
${ }^{14}$ Proofs are provided on demand.

${ }^{15}$ Unlike Gersbach and Schmutzler (2012), we do not explicitly consider strategic interactions such that the profit function would be written, for instance, as $\Pi\left(L_{i}, L-L_{i}\right)$, and $\Pi_{1}^{\prime}>0, \Pi_{2}^{\prime}<0$, leading to $\frac{d \Pi\left(L_{i}, L-L_{i}\right)}{d L_{i}}=\Pi_{1}^{\prime}-\Pi_{2}^{\prime}>0$. Since we do not restrict our approach to industry-specific training, we prefer to choose a general formulation.

${ }^{16}$ It is also the inverse supply function of skilled labour.

${ }^{17}$ As shown by Bernheim and Whinston, the truthful equilibria of common agency games are focal, having some interesting properties, including coalitionproofness.
} 
and that firms with wages below the minimum one have a zero supply of skilled labour.

Lemma 1: There is a symmetric equilibrium of the wage competition stage such that ${ }^{18} \quad W_{i}=W=$ $\Pi^{\prime}\left(\frac{L}{n}\right), i=1,2, . ., n$.

It follows from Lemma 1 that $W\left(\frac{L}{n}\right)=\Pi^{\prime}\left(\frac{L}{n}\right)$ is the inverse demand function for labour, which may equivalently be written as $W(a)=\Pi^{\prime} a \frac{\bar{L}}{n}$, as a function of $a=\frac{L}{L}$, i.e. of the proportion of skilled workers. The slope of the inverse demand function is $W^{\prime}(a)=\frac{\bar{L}}{n} \Pi^{\prime \prime}\left(a \frac{\bar{L}}{n}\right)<0$. In the spirit of Gersbach and Schmutzler, we shall consider from now on that the absolute value of this slope $\left|W^{\prime}(a)\right|$ is an inverse index of the degree of competitiveness. When it tends toward zero, we tend towards the case where the demand for labour is infinitely elastic at a given wage.

From Lemma 1, Firm $i$ receives net profits $V_{i}(L)=\Pi\left(\frac{L}{n}\right)-\frac{L}{n} \Pi^{\prime}\left(\frac{L}{n}\right)$ when the number of workers trained by the University is equal to $L$. These profits are net of the wages but include transfers to the University. Notice that $V_{i}^{\prime}(L)=$ $-\frac{L}{n^{2}} \Pi^{\prime \prime}\left(\frac{L}{n}\right)>0$ or, equivalently, if $a=\frac{L}{\bar{L}}$ is the proportion of skilled workers, $V_{i}^{\prime}(a)=-a \frac{\bar{L}^{2}}{n} \Pi^{\prime \prime}\left(a \frac{\bar{L}}{n}\right)=-a \frac{\bar{L}}{n} W^{\prime}(a)>0 \sqrt{a^{2}+b^{2}}$.

This simply means that skilled workers are a public good for the firms since their profits increase when the supply of skilled workers increase and that the benefit to each firm from an increase of the proportion of skilled workers is the inverse of the degree of competitiveness of the economy. The key assumption which is responsible for the 'public good result' is obviously $\Pi^{\prime \prime}\left(L_{i}\right)<0$ : firms' last stage equilibrium profits are supposed to increase at a decreasing rate with the number of skilled workers. The function $\Pi($.$) is the outcome$ of the last stage of the game where firms intervene, and possibly compete, on the output and other input markets. Gersbach and Schmutzler (2012) have convincingly argued that such a feature is associated with soft competition. Accordingly, we shall thereafter identify the speed at which individual equilibrium profits increase with the proportion of skilled workers with the inverse of the degree of competitiveness of the economy (or the industry).

Remark: If $\Pi^{\prime \prime}\left(L_{i}\right) \geq 0, \forall L_{i} \in[0, L], \quad$ the only possible equilibria of the wage competition stage are such that firms make zero net profits and, accordingly, that firms have no incentive to invest in training. More precisely, when $\Pi^{\prime}\left(L_{i}\right)$ is constant and equal to $f$, the common equilibrium wage is equal to $f$. When $\Pi^{\prime \prime}\left(L_{i}\right)>0, \forall L_{i} \in[0, L]$, only one firm is active in equilibrium, employs all skilled workers and the equilibrium wage is $W=$ $\Pi(L) / L$ since rivals would benefit from undercutting any larger wage. Accordingly, equilibrium firms' profits are zero, whatever the stock of skilled workers. There is both perfect competition and no incentive for firms to contribute to the training of workers.

Note that from Lemma 1 and Equation (2), we derive the equilibrium of the skilled labour market as follows: $W\left(\frac{L}{n}\right)-t=\omega\left(\frac{L}{L}\right)$, where $W\left(\frac{L}{n}\right)$ and $\omega\left(\frac{L}{L}\right)$ are, respectively, the inverse demand and the inverse supply for skilled labour.

\section{The common agency game}

We are now going to study the two first stages of the game defined in Section I, i.e. the common agency game $\Gamma \equiv\left\{\Re^{n+}, V_{0}, V_{1}, . ., V_{n}\right\}$, where $V_{1}, . ., V_{n}$ are the firms' gross profit functions which have been defined in Section III and $V_{0}$ are the University's net profits before any transfer from the firms. This game is, from the firms' point of view, a game of private production of a public good (skilled workers).

Denote by $C_{i} \geq 0$ the net contractual payoff which Firm $i$ requires for itself. We shall focus on the truthful equilibria of $\Gamma$ where the firms' sponsorship functions $T_{i}(L)$ are the following truthful strategies:

$$
T_{i}(L)=\max \left\{V_{i}(L)-C_{i}, 0\right\} .
$$

\footnotetext{
${ }^{18}$ It should be noticed that this equilibrium, which corresponds to the competitive equilibrium in the skilled labour market, is not the unique pure strategy Nash equilibrium of the wage competition game and has been selected among others. This is explained in more detail in Remark (wages' equilibrium) in the Appendix.
} 
By using truthful strategies, firms make the University a residual claimant which receives all the additional profits from any marginal increase in the number of workers which it trains. At a truthful equilibrium, Bernheim and Whinston (1986) have shown generally that the Agent's action should maximize the aggregate utility of the Principals and the Agent. ${ }^{19}$ Accordingly, at a truthful equilibrium, the number $L$ of students trained, when the University accepts all contract offers, must maximize here the sum of the firms and the University's net profits, $V_{0}(L)+\sum_{i \in N} V_{i}(L)$. From Equation (2) and Lemma 1 , the University gets net profits $V_{0}(L)=$ $\left(\Pi^{\prime}\left(\frac{L}{n}\right)-\omega\left(\frac{L}{L}\right)-c\right) L$ when training $L$ workers. On the other hand, we have shown from Lemma 1 that $V_{i}(L)=\Pi\left(\frac{L}{n}\right)-\frac{L}{n} \Pi^{\prime}\left(\frac{L}{n}\right), \quad i=1,2, . ., n$. Adding up, we obtain

$$
\begin{aligned}
V_{0}(L)+\sum_{i \in N} V_{i}(L)= & n \Pi\left(\frac{L}{n}\right) \\
& -L\left(c+\omega\left(\frac{L}{\bar{L}}\right)\right)
\end{aligned}
$$

i.e. the aggregate net profits of the Principals and the Agent equal the firms' gross profits minus the sum of the net wages paid to the skilled workers and of the training costs.

Notice that Function (4) is concave if

$$
\frac{1}{n} \Pi^{\prime \prime}\left(\frac{L}{n}\right)-\frac{2}{\bar{L}} \omega^{\prime}\left(\frac{L}{\bar{L}}\right)-\frac{L}{\overline{L^{2}}} \omega^{\prime \prime}\left(\frac{L}{\bar{L}}\right) \leq 0
$$

Given that $\Pi^{\prime \prime}\left(\frac{L}{n}\right)<0$, Condition (5) is always satisfied when the inverse demand function for training is not too convex, i.e. when

$$
\omega^{\prime}\left(\frac{L}{\bar{L}}\right)+\frac{L}{\bar{L}} \omega^{\prime \prime}\left(\frac{L}{\bar{L}}\right) \geq 0
$$

a familiar condition in the IO literature.

It follows that, when (5) holds, the equilibrium number of students trained $L_{N}$, when the University agrees to be sponsored by all firms, is the unique solution of

$$
\Pi^{\prime}\left(\frac{L}{n}\right)=c+\omega\left(\frac{L}{\bar{L}}\right)+\frac{L}{\bar{L}} \omega^{\prime}\left(\frac{L}{\bar{L}}\right) .
$$

The interpretation of this equality is simply that, at equilibrium, the benefit $\Pi^{\prime}\left(\frac{L}{n}\right)$ from a marginal increase in the employment of skilled workers must increase the cost to the firms and University $c+$ $\omega\left(\frac{L}{\bar{L}}\right)+\frac{L}{\bar{L}} \omega^{\prime}\left(\frac{L}{\bar{L}}\right)$ of such marginal increase. This marginal cost is equal to the unit cost of training at University $(c)$, plus the individual cost of training of the marginal student/worker $\left(\omega\left(\frac{L}{L}\right)\right)$ plus the effect on the skilled payroll of the induced increase of the individual cost of training of the marginal student/worker $^{20}\left(\frac{L}{\bar{L}} \omega^{\prime}\left(\frac{L}{L}\right)\right)$. Condition (6) is sufficient, though not necessary, to guarantee that the marginal cost of a skilled worker is increasing in the skilled employment level.

The equilibrium skilled employment level $L_{N}$ is increasing in the number $n$ of firms and decreasing in the training cost $c$.

In aggregate, firms pay at equilibrium to the University a marginal subsidy per student equal to $\sum_{i=1}^{n} V_{i}^{\prime}\left(L_{N}\right)=-\frac{L_{N}}{n} \Pi^{\prime \prime}\left(\frac{L_{N}}{n}\right)>0$.

Notice that the above equilibrium obtains also when, instead of the truthful contracts (3), the firms offer to the University simpler two-part sponsorship contracts $\mathbf{T}_{i}(\mathbf{L})=\max \left\{\mathbf{a}_{i}+\mathbf{b}_{i} \mathbf{L}, \mathbf{0}\right\}$. At equilibrium, $\quad \sum_{i=1}^{n} b_{i}=-\frac{L_{N}}{n} \Pi^{\prime \prime}\left(\frac{L_{N}}{n}\right)$ and $\sum_{i=1}^{n} a_{i}=V_{0}\left(L_{\emptyset}\right)-V_{0}\left(L_{N}\right)+\frac{L_{N}^{2}}{n} \Pi^{\prime \prime}\left(\frac{L_{N}}{n}\right)$.

Lemma 2: The equilibrium proportion of trained workers in the working population, $a_{N}=\frac{L_{N}}{\bar{L}}$ is a decreasing function of the number of workers per firm $\bar{l}=\frac{\bar{L}}{n}$ and of the training cost $c$.

The larger the number $\bar{l}$ of workers per firm, the lower, ceteris paribus, the equilibrium wage of skilled workers and, accordingly, the smaller the proportion $a_{N}$ of workers who choose to train. In the limit, when the number of firms tends to infinity and accordingly $\bar{l}$ tends towards 0 , the equilibrium wage of skilled workers and the proportion of workers who train reach their maximum value. Clearly, $\bar{l}$ is an inverse index of the degree of competition in the economy, which is also inversely related to the speed at which the marginal profitability of skilled labour

\footnotetext{
${ }^{19}$ Remember that they considered a transferable utility model.

${ }^{20}$ Notice that in order to induce more workers to train, one has to raise the wage received by all workers who train and not only by the marginal worker.
} 
decreases in each firm with the employment of skilled workers. We can safely conclude that the proportion of skilled labour should be larger in more competitive economies.

From Equations (2) and (7), the equilibrium tuition fee $t_{N}$ is given by

$$
t_{N}=c+a_{N} \omega^{\prime}\left(a_{N}\right) .
$$

This implies that, at equilibrium, students pay a tuition fee which is always larger than the training cost $c$. Under Equation (6), the tuition fee is a decreasing function of the number of workers per firm $\bar{l}$. Given Lemma 1, it then follows that students' aggregate expenditures on education decrease when the economy becomes less competitive, i.e. when $\bar{l}$ increases: this is both because there are less students and because the tuition fee is lower.

It remains to determine the equilibrium pay-offs of the firms net of transfers to the University $C_{i}^{*}$, $i=1,2, . ., n$. To this end, to the common agency game $\Gamma$ we associate a transferable utility and a cooperative game $P$ with the set of players being the set of firms: specifically, for each group $S$ of firms we calculate the highest joint pay-off $P(S)$ of the Agent (University) and Principals (firms). More precisely, for all subsets $S \subseteq N$, the maximum aggregate profits of the University and of the firms belonging to $S$ are

$$
P(S)=\max _{L}\left(V_{0}(L)+\sum_{i \in S} V_{i}(L)\right) .
$$

Notice that we denote $L_{S}=\operatorname{Arg} \max _{L}\left(V_{0}(L)+\sum_{i \in S} V_{i}(L)\right)$.

Lemma 3: At equilibrium, the aggregate firms' equilibrium profits net of transfers is such that

$$
\sum_{i=1}^{n} C_{i}^{*}=P(N)-P(\emptyset)
$$

with

$$
C_{i}^{*} \leq P(N)-P(N / i), i=1,2, \ldots, n
$$

and the University's profit is

$$
P(\emptyset)=V_{0}\left(L_{\emptyset}\right),
$$

$$
\text { where } L_{\emptyset}=\operatorname{Arg} \max _{L} V_{0}(L)
$$

Using the Envelope Theorem, it is then easy to see that the University's equilibrium profits per head are decreasing when $\bar{l}$ increases, i.e. when the economy becomes less competitive. Indeed,

$$
\frac{\left.d\left(V_{0}\left(L_{\emptyset}\right)\right) / \bar{L}\right)}{d \bar{l}}=\Pi^{\prime \prime}\left(a_{\emptyset} \bar{l}\right) a_{\emptyset}^{2}<0 .
$$

Corollary 1: At equilibrium, the firms' net aggregate contribution per head to the skilled workers' training equals

$$
e_{F}=\frac{1}{\bar{L}}\left(V_{0}\left(L_{\emptyset}\right)-V_{0}\left(L_{N}\right)\right)
$$

and aggregate expenditures on education per head equal

$$
\frac{V_{0}\left(a_{\emptyset}\right)}{\bar{L}}+c a_{N}
$$

We have already shown that University's profits per head and the proportion $a_{N}$ of trained workers are decreasing in $\bar{l}$, so that aggregate expenditures on education per head decrease with $\bar{l}$, i.e. equivalently, increase when the economy is more competitive.

It should be noticed that the equilibria of the common agency game described here correspond equivalently to the outcome of a cooperative game between the firms regarding the training of skilled workers.

\section{The linear-quadratic case}

Consider a product market with homogeneous good and zero production cost, and where one unit of product requires one unit of labour such as $q_{i}=L_{i}$. The demand for the product is given by $\left(\alpha-\frac{\beta}{2} L_{i}\right)$, hence Firm $i$ profit is given by $\Pi\left(L_{i}\right)=L_{i}(\alpha-$ $\left.\frac{\beta}{2} L_{i}\right)=\alpha L_{i}-\frac{\beta}{2} L_{i}^{2}$, where $\beta>0$ and $2 c>\alpha>c>0$, and $F(x)=x$. Let us denote $h=\beta \frac{\bar{L}}{n}$, and notice that $1 / h$ is competitiveness index. We accordingly obtain $\omega\left(\frac{L}{L}\right)=\frac{L}{\bar{L}}$ and $t_{N}=c+\frac{L}{\bar{L}}$. The equilibrium outcome is given in Result $1 .^{21}$

\footnotetext{
${ }^{21}$ Notice that we implicitly assume that $\frac{\bar{L}}{n} \geq \frac{1}{\beta}(a-c-2)$ in order to guarantee an interior solution, i.e. $L(N) \leq \bar{L}$.
} 
Result 1: At equilibrium, the total number of trained workers and the tuition fee are, respectively

$$
L_{N}=\bar{L} \frac{\alpha-c}{2+h}, \quad t_{N}=\frac{\alpha+c(1+h)}{2+h}
$$

thus, the aggregate profits of the University and the firms are given by

$$
P(N)=\bar{L} \frac{(\alpha-c)^{2}}{2(2+h)}
$$

The proportion of skilled workers is increasing in $(\alpha-c)$ and decreasing in $h$, meaning that it is more important in more competitive economies. The tuition fee is decreasing in $h$ and always larger than the training cost.

Generally, equilibrium firms' expenditures on education per worker are obtained as $e_{F}=\frac{V_{0}\left(L_{\emptyset}\right)-V_{0}\left(L_{N}\right)}{\bar{L}}$. Result 2 provides the equilibrium value of the firms' expenditures on education per worker and the share of firms in the financing of education.

Result 2: At equilibrium, total firms' expenditures on education per worker are given by

$$
e_{F}=\frac{(\alpha-c)^{2} h^{2}}{4(1+h)(2+h)^{2}}
$$

thus, the share of firms in the financing of total training expenditures is obtained as

$$
s_{F}=\frac{h^{2}(\alpha-c)}{(2+h)(2(\alpha+c)+h(\alpha+3 c))}
$$

The firms' expenditures on education per worker are positive if $\beta \in 0,+\infty$. Starting from 0 when $h=0$, they are increasing in $h$ for $h \in 0,1+\sqrt{5}$ ] and decreasing in $h$ for $h \geq 1+\sqrt{5}$, tending towards 0 as $h$ tends towards infinity. This result is very interesting, given that $h$ is inversely related to the competitiveness of the economy. It indeed shows that the relationship between the investment of firms in training and the competitiveness of the economy is nonmonotonic. It is low both in very competitive economies and in very noncompetitive ones.

Not surprisingly, the proportion of skilled workers who would not have been trained if there had not been subsidies to education evolves exactly in the same way. Indeed, this proportion equals

$$
a_{N}-a_{\emptyset}=\frac{\alpha-c}{2+h}-\frac{\alpha-c}{2(1+h)}=\frac{h(\alpha-c)}{2(1+h)(2+h)}
$$

It is the difference between the equilibrium proportion $a_{N}$ of skilled workers and the proportion $a_{\emptyset}$ of skilled workers in the case when the University refuses the firms' subsidies. It is first increasing from 0 , takes a maximum and then decreases, tending towards zero as $h$ tends towards infinity.

The intuition for these results is simple. When the economy is increasingly competitive ( $h$ is smaller), the marginal productivity labour and hence the equilibrium wage of skilled workers, $\alpha-a h$, is less sensitive to any variation in the proportion $a$ of skilled labour, so that there is less incentive for the firms to see more workers trained. In the limit, as $h \rightarrow 0$, the economy becomes perfectly competitive and skilled labour is no more a public good from the firms' point of view.

In the opposite case, as the economy becomes less and less competitive, the equilibrium proportions of trained workers both at equilibrium when all firms sponsor education and in the case where the University refuses all subsidies decrease because the equilibrium skilled wage goes down and with it the incentive to train. Accordingly, the additional number of workers which are trained thanks to firms' subsidies decreases: the difference $a_{N}-a_{\emptyset}$ goes to zero as $h$ goes to infinity.

In Figure A2 in the Appendix, we have pictured the aggregate and the firms' expenditures per head on education, respectively, $e$ and $e_{F}$, as a function of $h$ for $\alpha=\frac{3}{2}$ and $c=1$. Remember that we have already shown that aggregate expenditures per head on education decrease with $h$, i.e. are the larger when the economy is the more competitive.

If aggregate firms' expenditures on training per capita are a nonmonotonic function of the competitiveness of the economy, the share of firms in the financing of education is inversely related to the competitiveness of the economy as depicted in Figure A3 in the Appendix. Indeed, $s_{F}$ is increasing in $h$, tending towards $\frac{\alpha-c}{\alpha+3 c}<1$ when $h$ tends towards infinity, as pictured in Figure 3. It is decreasing in the unit training cost $c$ and increasing in $\alpha$. The reason for different evolutions is simply that when the economy becomes less competitive, the firms spend less per capita on training but, at the same time, students' 
expenditures decrease even faster, so that the share of firms in education expenditures increases. Considering several universities or the case where the University is a public instead of a private one does not change qualitatively the above results. ${ }^{22}$

\section{Conclusion}

In this article, we have extended the contribution of Gersbach and Schmutzler (2012) who proved that product market imperfections may affect firms' expenditures on training. In our model, we assumed that students are trained at higher schools rather than on the job only and considered skills who are possibly useful across industries and within countries rather than necessarily industry-specific. We also considered that qualification is produced by universities and that firms subsidize universities to train a given number of future workers. If it is impossible to distinguish students directly trained by the firms, the model allows to determine the additional number and proportion of students who get skilled, thanks to firms' subsidies to the University.

We obtained some new results. The first is that the fiercer is product market competition the greater is the proportion of skilled workers in one economy; hence, more competitive countries should have a larger proportion of skilled workers. The second result is that the firms' training expenditures per worker is nonmonotonic with respect to the competitiveness of the economy. Finally, the share of firms in financing general training is, however, monotonic with respect to the competitiveness of the economy.

These results have been shown to be robust to the introduction of competition between several different private universities.

So our model provides a possible explanation of the observation, reported in Section I for eight European countries, that countries with the higher proportions of skilled workers are at the same time characterized by lower participation of firms in the financing of education. Though the model may be somewhat specific, we are confident that the results may be rather robust. Indeed, the intuition seems quite general. On one hand, a less competitive economy means a lower skilled wage and accordingly less workers' incentives to acquire skills, leading naturally to a lower proportion of skilled workers. On the other hand, less competition means that the equilibrium skilled wage decreases more steeply with the supply of skilled labour, so that firms have more incentives to invest in increasing the stock of skilled workers.

We can extend our investigation in several directions. We could for instance analyse how globalization might affect the firms' training expenditures on training opening the education and product markets internationally.

\section{Disclosure statement}

No potential conflict of interest was reported by the authors.

\section{ORCID}

H. Lasram (D) http://orcid.org/0000-0003-2608-070X

\section{References}

Acemoglu, D. 1997. "Training and Innovation in an Imperfect Labour Market." The Review of Economic Studies 64: 445-464. doi:10.2307/2971723.

Acemoglu, D., and J. S. Pischke. 1998. "Why Do Firms Train? Theory and Evidence." The Quarterly Journal of Economics 113: 79-119. doi:10.1162/003355398555531.

Acemoglu, D., and J. S. Pischke. 1999a. "The Structure of Wages and Investment in General Training." NBER Working Paper No. 6357. Cambridge, MA: National Bureau of Economic Research.

Acemoglu, D., and J. S. Pischke. 1999b. "Beyond Becker: Training in Imperfect Labour Markets." Economic Journal 109: 112-142. doi:10.1111/ecoj.1999.109.issue453.

Autor, D. H. 2001. "Why Do Temporary Help Firms Provide Free General Skills Training?” The Quarterly Journal of Economics $116 \quad$ (4): 1409-1448. doi:10.1162/ 003355301753265615.

Bassanini, A., and G. Brunello. 2010. "Barriers to Entry, Deregulation and Workplace Training: A Theoretical Model with Evidence from Europe." European Economic Review 55(8): 1152-1176. doi:10.1016/j. euroecorev.2011.05.004.

Becker, G. S. 1962. "Investment in Human Capital: A Theoretical Analysis." Journal of Political Economy 70 (5, Part 2): 9-49. doi:10.1086/258724.

Becker, G. S. 1964. Human Capital: A Theoretical and Empirical Analysis, with Special Reference to Education. New York: Columbia University Press.

Bernheim, D., and M. Whinston. 1986. "Menu Auctions, Resource Allocation and Economic Influence." The

\footnotetext{
${ }^{22}$ Computing details are available on demand.
} 
Quarterly Journal of Economics 101: 1-32. doi:10.2307/ 1884639.

Chang, C., and Y. Wang. 1995. "A Framework for Understanding Differences in Labor Turnover and Human Capital Investment." Journal of Economic Behavior and Organization 28 (1): 91-105. doi:10.1016/ 0167-2681(95)00022-9.

Chang, C., and Y. Wang. 1996. "Human Capital Investment under Asymmetric Information: The Pigovian Conjecture Revisited." Journal of Labor Economics 14 (3): 505-519. doi:10.1086/209820.

Gersbach, H., and A. Schmutzler. 2012. "Product Markets and Industry Specific Training." The RAND Journal of Economics 43: 475-491. doi:10.1111/rand.2012.43. issue-3.

Grlitz, K., and J. Stiebale. 2008. "Does Product Market Competition Decrease Employers' Training Investments? Evidence from German Establishment Panel Data." Ruhr

\section{Appendix}

Proof of Lemma 1. Let us show that this is indeed an equilibrium, i.e. that no firm can benefit from deviating. At equilibrium, from the equal sharing rule, $L_{i}=\frac{L}{n}, i=$ $1,2, . ., n$. First notice that equilibrium profits $\pi(L)=\Pi(L)-$ $L \Pi^{\prime}(L)$ are strictly increasing in $L$, since $\pi(0) \geq 0$ and $\pi^{\prime}(L)=-L \Pi^{\prime \prime}(L)>0$. If a firm $i$ deviates to some $W_{i}<W$, it obtains net profits $\pi(0)=\Pi(0)$ lower than its equilibrium profits $\pi\left(\frac{L}{n}\right)$. If it deviates to some $W_{i}>W$, it obtains profits $\Pi(L)-W_{i} L<\Pi(L)-\Pi^{\prime}\left(\frac{L}{n}\right) L<\pi\left(\frac{L}{n}\right)$.

Remark (Wages' equilibrium): It is easy to show that any $n$-tuple such that $W_{i}=W, \quad i=1,2, . ., n, \quad$ and $W \in$ $\left(\frac{\Pi(L)-\Pi\left(\frac{L}{n}\right)}{L-\frac{L}{n}}, \frac{\Pi\left(\frac{L}{n}\right)}{\frac{L}{n}}\right]$ is an equilibrium of this game. This is because (i) it yields positive profits to all firms, (ii) any deviation towards a lower wage would result in lower (zero) profits to the deviating firm and (iii) any deviation towards a higher wage would result in lower profits to the deviating which would have to hire all skilled workers. We shall, however, focus on the competitive equilibrium of Lemma 1. To understand why, let us consider the following slightly perturbed game, inspired from Salop (1979) 'circular city' model. Suppose that the $L$ skilled workers differ by their preferences for the $n$ firms: They are uniformly distributed over a circle and incur a linear transportation cost $\tau d_{i}$ for working at a firm $i$ which is located at a distance $d_{i}$ from their own location, $\tau$ being the transportation cost parameter. $^{23}$ The $n$ firms are equidistantly located on the circle. The model analysed above is the limit when $\tau \rightarrow 0$ of this model of imperfect competition in the skilled labour market. It is easy to see that, for all $\tau>0$, the
Economic Paper No. 41. Essen: Department of Economics, Ruhr-Universität Bochum (RUB).

Grossman, G. M., and E. Helpman. 1994. "Protection for Sale." American Economic Review 84: 833-850.

Katz, E., and A. Ziderman. 1990. "Investment in General Training: The Role of Information and Labour Mobility." The Economic Journal 100 (403): 1147-1158. doi:10.2307/ 2233964.

Laussel, D., and M. Le Breton. 2001. "Conflict and Cooperation: The Structure of Equilibrium Payoffs in Common Agency." Journal of Economic Theory 100: 93128. doi:10.1006/jeth.2000.2702.

Picchio, M., and J. C. Van Ours. 2010. "Market Imperfections and Firm-Sponsored Training." Labour Economics 18: 712-722.

Salop, S. 1979. "Monopolistic Competition with Outside Goods." The Bell Journal of Economics 10: 141-156. doi: $10.2307 / 3003323$.

imperfect competition model has a unique equilibrium such that $W_{i}=W=\Pi^{\prime}\left(\frac{L}{n}\right)-\frac{\tau}{n}, i=1,2, . ., n$. The limit of this equilibrium when $\tau \rightarrow 0$ is the equilibrium analysed in Lemma 1, which can be then seen as selected from the set of Nash equilibria described above by introducing an infinitesimal transportation cost.

Proof of Lemma 2. It is easy to rewrite (7) as

$$
\Pi^{\prime}\left(a_{N} \bar{l}\right)=c+\omega\left(a_{N}\right)+a_{N} \omega^{\prime}\left(a_{N}\right)
$$

Differentiating totally yields

$$
\begin{aligned}
& \left(\bar{l} \Pi^{\prime \prime}\left(a_{N} \bar{l}\right)\right)-2 \omega^{\prime}\left(a_{N}\right)-a_{N} \omega^{\prime \prime}\left(a_{N}\right) d a+\left(a_{N} \Pi^{\prime \prime}\left(a_{N} \bar{l}\right)\right) d \bar{l}-d c \\
& \quad=0
\end{aligned}
$$

Under (5) the result holds trivially.

Proof of Lemma 3. (i) Since the $n$ functions $V_{i}(L)$ are strictly increasing in $L$, this common agency game is clearly comonotonic, and $P$ is therefore convex, according to Definition 4.1 and Proposition 4.1 in Laussel and Le Breton (2001, 106). Since $P$ is convex, the common agency game $\Gamma$ has the 'no-Rent Property' according to Theorem 3.2 in Laussel and Le Breton (2001), what means that the University's profits are equal to the profits $P(\emptyset)=V_{0}\left(L_{\emptyset}\right)$, which it obtains when it rejects all firms' contract offers and education is financed only by students tuition fees. Equation (8) follows directly. The Firms share between themselves the difference between the aggregate profits of the vertical structure, when the University contracts with all of them, and the University's profits when it stands on its own, that is their collective contribution to aggregate profits.(ii) The exact sharing of this difference between the firms is not determined in equilibrium but the equilibrium net profits of a

\footnotetext{
${ }^{23}$ Needless to say, the utility of a skilled worker from working at $i$ is simply $W_{i}-\tau d_{i}$.
} 


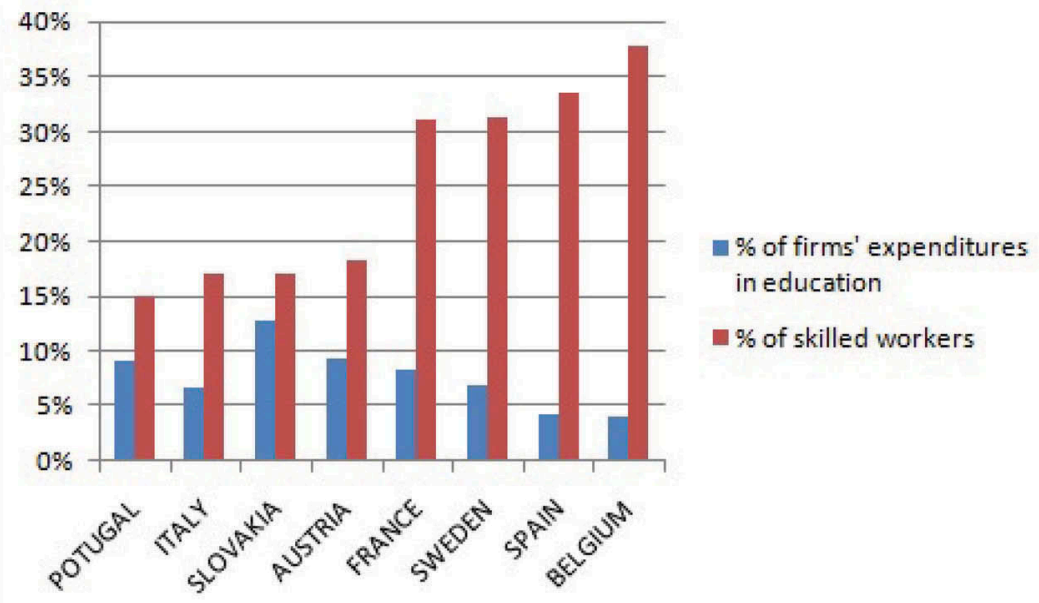

Figure A1. Firms' share of higher education expenditures and \% of skilled workers in the working population over eight European countries.

given firm should not be larger than its own contribution to aggregate profits, since otherwise its contract proposal would be rejected. Equation (9) follows. Notice that, from convexity of $\Gamma, \quad \sum_{i=1}^{n} P(N)-P(N / i) \leq P(N)-P(\emptyset)$.

Proof of Corollary 1. (i) The net aggregate contribution of the firms to the skilled workers' training must equal the difference between University profits when it stands on its own and University profits when it is sponsored by the firms, given that the firms have to compensate the University for training a larger number of students than the one which maximizes its operating (net) profits. In per capita terms, we obtain Equation (10). Notice that $e_{F}$ is strictly positive since $L_{\emptyset}=\operatorname{Arg} \max _{L} V_{0}(L)$ so that $V_{0}\left(L_{\emptyset}\right)>V_{0}\left(L_{N}\right)$.(ii) Since the students' contribution to their own training is $t^{*}\left(L_{N}\right) L_{N}$, aggregate expenditures on education are equal to

$$
t^{*}\left(L_{N}\right) L_{N}+V_{0}\left(L_{\emptyset}\right)-V_{0}\left(L_{N}\right)=V_{0}\left(L_{\emptyset}\right)+c L_{N}
$$

so that expenditures on education per head equal $\frac{V_{0}\left(a_{\emptyset}\right)}{\bar{L}}+c a_{N}$.

Proof of Result 1. We substitute $\Pi^{\prime}\left(\frac{L}{n}\right)=\alpha-\beta \frac{L}{n}, \omega\left(\frac{L}{L}\right)=\frac{L}{\bar{L}}$ and $\omega^{\prime}\left(\frac{L}{L}\right)=1$ in Equation (7), and solving with respect to $L$, we obtain $L_{N}=\bar{L} \frac{\alpha-c}{2+h}$. Substituting $L_{N}$ in $t_{N}=c+a_{N} \omega^{\prime}\left(a_{N}\right)$, we obtain the equilibrium tuition fee.

Proof of Result 2. When the University rejects all contracts, it maximizes $V_{0}(L)=\left(\Pi^{\prime}\left(\frac{L}{n}\right)-\omega\left(\frac{L}{L}\right)-c\right) L \quad$ training $L_{\emptyset}=\frac{(\alpha-c) \bar{L}}{2(h+1)}$. According to the equilibrium given in Result 1, we compute $e_{F}=\frac{V_{0}\left(L_{\emptyset}-V_{0}\left(L_{N}\right)\right.}{\bar{L}}$, aggregate expenditures per worker on education are $e=e_{F}+\frac{t_{N} L_{N}}{\bar{L}}$. Finally, the share of firms in financing training is then given by $s_{F}=\frac{e_{F}}{e}$.

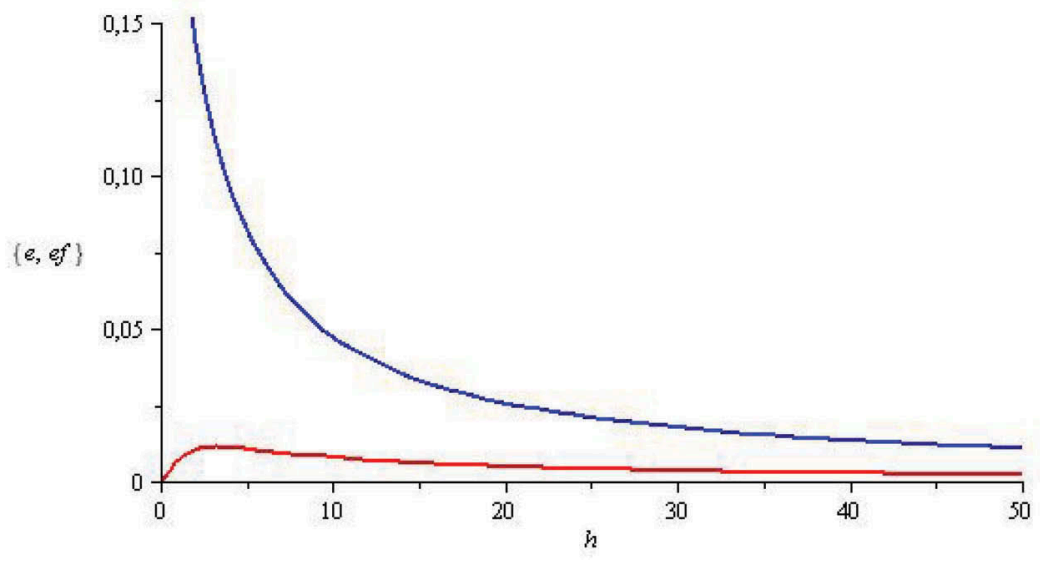

Figure A2. Total and firms' training expenditures as function of $h$. 


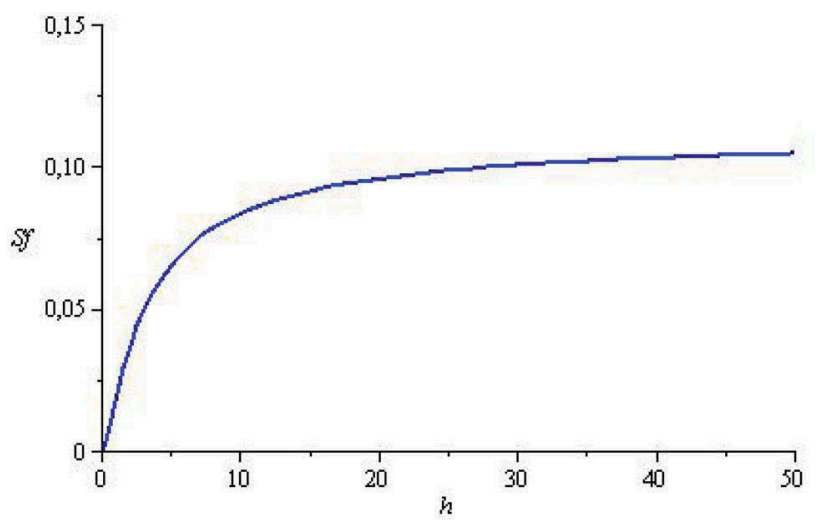

Figure A3. Share of firms in training expenditures as function of $h$. 